'Laboratorio de Bacteriología Molecular. Departamento de Bioanálisis. Universidad de Oriente, Estado Sucre-Venezuela ¿Laboratorio de Biología de Plásmidos. Instituto de Biología Experimental. Universidad Central de Venezuela. Caracas-Venezuela.

El trabajo fue financiado por el Consejo de Investigación de la Universidad de Oriente. Núcleo Sucre (PCl: 20401021253105) y el Consejo de Desarrollo Científico y Humanístico de la Universidad Central de Venezuela (PI-03335417 y PG-03335416).

Recibido el 17 de marzo de 2009, aceptado el 19 de enero de 2010.

Correspondencia a: Dra. Militza Guzmán Calle Bolívar. Antigua Escuela de Enfermeras. Primer piso, Departamento de Bioanálisis. Universidad de Oriente. Cuma-

ná, Estado Sucre, Venezuela. Teléfono: 0058-04166930701. Fax: 0058-0293-4311175.

E-mail:miltzaguz@cantv.net

\section{Caracterización de la región variable de integrones clase 1 presentes en cepas nosocomiales de Klebsiella pneumoniae}

\author{
MILITZA GUZMÁN ${ }^{1,2}$, GUILLERMINA ALONSO²
}

\section{Characterization of the variable region within class 1 integrons in Klebsiella pneumoniae nosocomials strains}

\begin{abstract}
Background: Integrons are responsible for the capture and dissemination of resistance genes in Gram negative bacteria. Aim: To characterize the variable region within class 1 integrons in nosocomial strains of Klebsiella pneumoniae. Material and Methods: Twenty nine Klebsiella pneumoniae strains isolated from hospitalized patients were analyzed. The variable region of class 1 integrons was characterized by polymerase chain reaction and direct sequencing. Genetic localization of class 1 integrons was determined by bacterial conjugation. Results: Ten strains contained class 1 integrons, with sizes ranging from 750 to 2000 base pairs. One integron element was present in nine strains and two elements in one single strain. integrons were associated to plasmids. Cassettes aadA, aac(6)-Iq, orfD, dfrA]7, aadA5 and aadB were found. Conclusions: The presence of class 1 integrons may play an important role in the dissemination of hospital resistance against aminoglycosides.
\end{abstract}

(Rev Med Chile 2010; 138: 322-329).

Key words: Bacterial infections; Integrons; Klebsiella pneumoniae.
L as infecciones nosocomiales causadas por microorganismos multiresistentes han sido reconocidas como una importante causa de morbimortalidad en los pacientes hospitalizados ${ }^{1}$. La multiresistencia es atribuida en primer lugar a la adquisición de moléculas plasmídicas, sin embargo, diversos estudios han demostrado la presencia de genes de resistencia en otros elementos genéticos conocidos como integrones ${ }^{2-4}$.

Un integrón es un elemento genético dinámico, que funciona como un sistema de captura de genes y provee un mecanismo para la adquisición y diseminación de genes de resistencia, el cual puede localizarse en plásmidos, transposones e incluso en el cromosoma bacteriano. En base a la secuencia del gen de la integrasa presente en los integrones, se han reportado más de nueve clases, siendo los integrones clase 1 los que con mayor frecuencia se han asociado a bacterias Gram negativas ${ }^{5,6}$.
Un integrón clase 1 está conformado por dos regiones conservadas de ADN situadas en los extremos, denominadas 5' CS y 3' CS y una región variable ubicada entre las dos anteriores. En el extremo 5' CS se encuentra el gen intI que codifica para una integrasa encargada de catalizar una recombinación genética sitio específico; continuo a éste se encuentra la secuencia att 1 , que es el sitio de recombinación específico donde se insertan los casetes génicos separados por regiones intergénicas de aproximadamente $10 \mathrm{pb}$; entre intI y attI están los promotores $\mathrm{P}_{c}$ y $\mathrm{P}_{\mathrm{i}}$ los cuales dirigen la expresión de los genes presentes en el casete y el gen int $\Gamma$. La región variable es donde se insertan los diferentes casetes génicos, que de acuerdo a estudios de secuenciación, son en su mayoría, pero no exclusivamente, genes que codifican resistencia a los antimicrobianos ${ }^{8,9}$. En el extremo 3' CS se localizan tres tipos de genes qacE 1, sul1 y orf5, 
el primero confiere resistencia a compuestos de amonio cuaternario que forman parte de algunos antisépticos y desinfectantes, el segundo confiere resistencia a sulfonamidas y el orf5 es de función desconocida ${ }^{10}$.

Klebsiella pneumoniae es considerada una especie patógena-oportunista para el hombre ${ }^{11}$. A partir de 1998 en Venezuela y América Latina se ubica entre los principales patógenos causantes de cuadros clínicos a nivel nosocomial ${ }^{12}$. La presencia de ciertos mecanismos de resistencia, como producción de enzimas $\beta$-lactamasas (tipo $\mathrm{SHV}$, TEM, CTX, GES, AmpC entre otras), enzimas modificadoras de aminoglucósidos, cloranfenicolacetiltransferasas y Qnr, han originado fallas terapéuticas en el tratamiento de las infecciones causada por K. pneumoniae ${ }^{13,14}$.

En los últimos años los integrones clase 1 han sido considerados como elementos importantes en la diseminación de genes que confieren resistencia a los $\beta$-lactámicos, aminoglucósidos y quinolonas en K. pneumoniae y más de 60 genes que confieren resistencia a los antimicrobianos de interés clínico han sido reportados en la región variable de integrones clase $1^{15,16}$.

Debido a que los integrones juegan un papel importante en la captura y diseminación de genes de resistencia, el objetivo de este trabajo fue caracterizar los casetes génicos presentes en la región variable de dichos elementos genéticos en cepas nosocomiales de K. pneumoniae.

\section{Material y Métodos}

\section{Cepas Bacterianas}

Se estudiaron 29 cepas de K. pneumoniae provenientes de pacientes con infección nosocomial, atendidos en diferentes áreas de hospitalización del Servicio Autónomo Hospital Universitario "Antonio Patricio de Alcalá", durante el período comprendido entre junio del 2003 y mayo 2004. A la hora de seleccionar las cepas se mantuvo el criterio de seleccionar una cepa por paciente.

\section{Pruebas de Sensibilidad a los antimicrobianos}

La susceptibilidad a los agentes antimicrobianos se realizó mediante el método de difusión en disco, siguiendo los lineamientos propuestos para enterobacterias por el Clinical and Laboratory Standards Institute (CLSI) ${ }^{17}$. Se ensayaron los siguientes agentes antimicrobianos: cefotaxima, ceftazidima, ceftriaxona, aztreonam, imipenen, amikacina, kanamicina, tobramicina, cefepima, gentamicina, tetraciclina, cloranfenicol, ciprofloxacina y amoxicilina/ácido clavulánico.

\section{Extracción de ADN genómico}

La extracción de ADN total se realizó mediante el método de ebullición ${ }^{18}$. En un tubo Eppendorf se mezclaron $200 \mu \mathrm{l}$ de un cultivo de la cepa crecido durante 18 horas con $800 \mu \mathrm{l}$ de agua estéril, la mezcla fue sometida a ebullición durante 10 minutos y se centrifugó a $12.000 \mathrm{~g}$ durante 3 minutos. El sobrenadante con el contenido de ADN total se almacenó a $-20^{\circ} \mathrm{C}$ hasta su uso.

\section{Amplificación de la región variable de los integrones clase 1}

La presencia de los genes insertados en la región variable de los integrones clase 1 se determinó utilizando los oligonucleótidos: 5' CS:5-'GGC ATC CAA GCA GCA A-3' y 3' CS:5'-AAG CAG ACT TGA CCT GA 3-' los cuales son complementarios a los segmentos 5'CS y $3^{\prime} \mathrm{CS}^{18}$. Las condiciones de reacción fueron $94^{\circ} \mathrm{C}$ por $5 \mathrm{~min}, 94^{\circ} \mathrm{C}$ por $1 \mathrm{~min}$, $60{ }^{\circ} \mathrm{C}$ por $1 \mathrm{~min}, 72^{\circ} \mathrm{C}$ por 1 min durante 30 ciclos, con una extensión final de $72{ }^{\circ} \mathrm{C}$ por $10 \mathrm{~min}$. Se empleó como control negativo un lisado celular de la cepa de Escherichia coli J62-2, la cual no presenta integrones y un segundo control negativo que consistió en mezclar todos los componentes sin ADN molde, utilizando agua para completar el volumen (control de reactivos). Como control positivo se empleó un lisado de la cepa K. pneumoniae T9701, la cual presenta un integrón de 750 pb. Los productos de la PCR fueron corridos en un gel de agarosa al 1\% teñidos con bromuro de etidio y visualizados en un Gel Doc (Bio-Rad).

\section{Conjugación Bacteriana y aislamiento de plásmidos}

A las cepas de K. pneumoniae que presentaron integrones clase 1 , se les realizó conjugación bacteriana en medio sólido ${ }^{19}$. Como cepa receptora se empleó E. coli J62-2 (CVCM131) la cual presenta el genotipo F-, his, pro, trp, lac, rif. Las cepas donantes y la receptora, fueron crecidas en caldo Luria Bertani a $37^{\circ} \mathrm{C}$ durante toda la noche. Las transconjugantes fueron seleccionadas en agar MacConkey, suplementado con amikacina (20 $\mu \mathrm{g} / \mathrm{ml})$ o kanamicina $(50 \mu \mathrm{g} / \mathrm{ml})$ según el perfil de resistencia de cada cepa donante. A cada cepa 
Caracterización de la región variable de integrones clase 1 presentes en Klebsiella pneumoniae - M. Guzmán et al

transconjugante se le determinó la susceptibilidad antimicrobiana, según el CLSI ${ }^{17}$.

Con el propósito de determinar la localización de los integrones, se procedió a extraer el ADN plasmídico en las cepas donantes y transconjugantes empleando la técnica modificada de lisis alcalina ${ }^{20}$. Los productos de la extracción se sometieron a electroforesis en gel de agarosa $(0,7 \%)$, fueron coloreados con bromuro de etidio y visualizados en un equipo Gel Doc (Bio-Rad).

\section{Secuenciación de la región variable}

La secuenciación de las regiones variables detectadas en las cepas donantes y transconjugantes se realizó en el Centro de Secuenciación y Análisis de Ácidos Nucleicos (CeSAAN), ubicado en el Centro de Microbiología del Instituto Venezolano de Investigaciones Científicas (IVIC), empleando un secuenciador Perkin-Elmer modelo ABI PRISM ${ }^{\mathrm{TM}} 377$, previa purificación de los productos de PCR. La búsqueda de similitudes en la base de datos GenBank, se hizo vía internet (http://WWW.ncbi.nlm. nih.gov) empleando los servicios BLAST (Basic Local Alignment Search Tool) ${ }^{21}$.

\section{Resultados}

Se encontraron 7 cepas con resistencia a 10 antimicrobianos, 5 resistentes a la combinación de 12,4 para 11 y 3 para la combinación de 14. Para combinaciones menores de 10 antimicrobianos se encontraron: 5 cepas para 6 combinaciones; 2 para 7 y 8 combinaciones respectivamente, y 1 para 5 combinaciones. Los mayores porcentajes de resistencia se presentaron para los -lactámicos y aminoglucósidos (Tabla 1).
Tabla 1. Perfil de resistencia presentado por las cepas nosocomiales de Klebsiella pneumonia

\begin{tabular}{|c|c|}
\hline Cepa & Perfil de resistencia \\
\hline Kp01 & ATM CAZ AMK K TOB GEN Nt CHL \\
\hline Kp02 & ATM CAZ AMK K TOB GEN Nt CHL \\
\hline Kp03 & ATM CAZ AMK K TOB GEN Nt CHL TCY CIP \\
\hline Kp04 & AMK K TOB GEN Nt TCY \\
\hline Kp05 & ATM CAZ CRO CTX CHL TCY \\
\hline Kp06 & ATM CAZ AMK K TOB GEN Nt CHL TCY CIP OFLO \\
\hline Kp07 & ATM CAZ CRO CTX CHL TCY \\
\hline Kp08 & ATM CAZ AMK K TOB GEN Nt C TCY CIP \\
\hline Kp09 & TZP ATM CAZ CRO CTX FEP AMK K TOB GEN Nt CHL \\
\hline Kp10 & TZP ATM CAZ CRO CTX AMK K TOB GEN Nt CHL TCY CIP OFX \\
\hline Kp11 & TZP ATM CAZ CRO CTX FEP AMK K TOB GEN Nt CHL \\
\hline Kp12 & AMK K TOB GEN Nt \\
\hline Kp13 & TZP ATM CAZ CRO CTX FEP AMK K TOB GEN Nt CHL TCY OFX \\
\hline Kp14 & ATM CAZ CRO CTX AMK K TOB GEN Nt CHL \\
\hline Kp15 & TZP ATM CAZ CRO CTX FEP AMK K TOB GEN Nt CHL TCY OFX \\
\hline Kp16 & ATM CAZ CRO CTX TOB GEN TCY \\
\hline Kp17 & ATM CAZ CRO CTX AMK K TOB GEN Nt CHL \\
\hline Kp18 & ATM CAZ CRO CTX AMK K TOB GEN Nt CHL \\
\hline Kp19 & ATM CAZ CRO CTX TOB GEN \\
\hline Kp20 & ATM CAZ CRO CTX TOB GEN \\
\hline Kp21 & ATM CAZ CRO CTX AMK K CHL \\
\hline Kp22 & ATM CAZ CRO CTX AMK K TOB GEN Nt CHL \\
\hline Kp23 & ATM CAZ CRO CTX AMK K TOB GEN Nt CHL \\
\hline Kp24 & ATM CAZ CRO CTX AMK K TOB GEN Nt CHL TCY \\
\hline Kp25 & ATM TZP CAZ CRO CTX AMK K TOB GEN Nt CHL OFX \\
\hline Kp26 & ATM TZP CAZ CRO CTX AMK K TOB GEN Nt CHL OFX \\
\hline Kp27 & ATM TZP CAZ CRO CTX AMK K TOB GEN Nt CHL TCY \\
\hline Kp28 & ATM TZP CAZ CRO CTX AMK K TOB GEN Nt TCY \\
\hline Kp29 & ATM TZP CAZ CRO CTX AMK K TOB GEN Nt TCY \\
\hline
\end{tabular}

Kp: Klebsiella pneumoniae, AMK: Amikacina, ATM: Aztreonam, CAZ: Ceftazidima, CHL: Cloramfenicol, CIP: Ciprofloxacina, CRO: Ceftriaxona, CTX: Cefotaxima, FEP: Cefepima, GEN: Gentamicina, K: Kanamicina, Nt: Netilmicina, OFX: Ofloxacina, TCY: Tetraciclina, TOB: Tobramicina, TZP: piperacilina-tazobactam. 


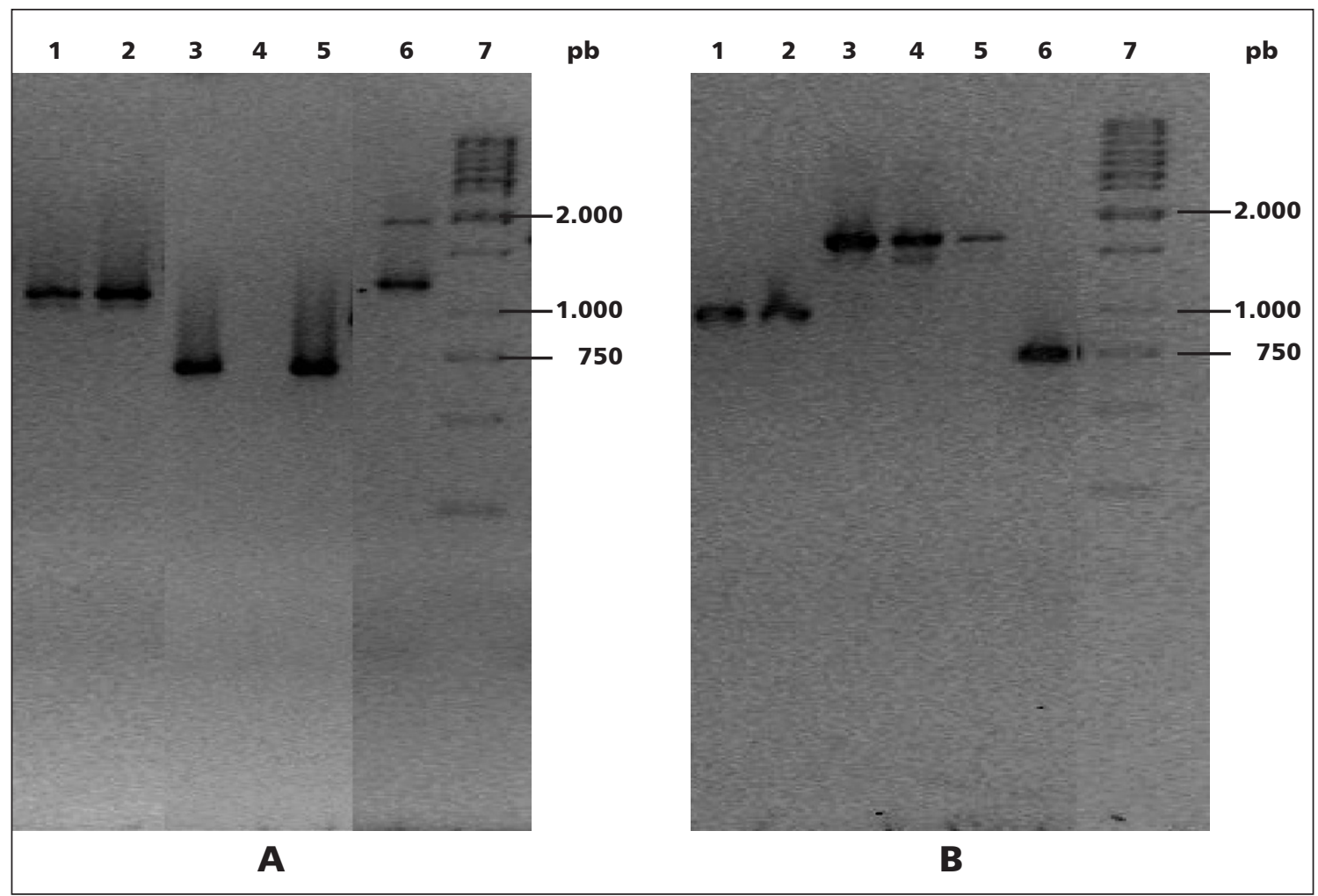

Figura 1. Amplificación de la región variable de integrones clase 1 mediante PCR. A. Integrones clase 1 en plásmidos conjugativos, aislados de las cepas transconjugantes. Líneas 1 a 7. T13, T15, T28, Control negativo, Control positivo, T14, Marcador de peso molecular. B. Integrones clase 1 en plásmidos no conjugativos, aislados de las cepas donantes. Línea 1 a 7. Kp09, Kp11, Kp25, Kp26, Kp27, Control positivo, Marcador de peso molecular. T: transconjugantes, Kp: Klebsiella pneumoniae, kb: kilobases.

En las cepas transconjugantes se observó un fenotipo de resistencia semejante al de la célula donante. En todas las cepas donantes se observó la presencia de un plásmido de alto peso molecular $(>40 \mathrm{~kb})$ el cual fue transferido a las células de $E$. coli con una frecuencia de conjugación de $10^{-2} \mathrm{y}$ $10^{-3}$ transconjugantes/células donante (Datos no mostrados).

La amplificación para la región variable demostró que $34,5 \%$ (10/29) de las cepas presentaron integrones clase 1 . Con respecto al número de elementos genéticos identificados nueve cepas $(09,11,13,15,25,26,27,28,29)$ presentaron un integrón y una cepa (14) presentó dos elementos. El tamaño de los fragmentos amplificados osciló de 750 a 2000 pb. En 4 cepas el amplicón fue de $1000 \mathrm{pb}$, en 3 de $1700 \mathrm{pb}$, en dos de 750 pb y en una de 1200 y 2000 pb (Figura 1).

La presencia de integrones clase 1 fue detectada en todos los aislamientos plasmídicos. Los amplificados de 750, 1.200, 2.000 y 1.000 pb se encontraron en plásmidos conjugativos, mientras que los de $1.700 \mathrm{pb}$ estaban localizados en plásmidos no conjugativos. Sólo el amplificado de $1.000 \mathrm{pb}$ se detectó en ambos tipos de plásmidos (Figura 1).

De acuerdo con el alineamiento en nucleótidos, se lograron identificar los casetes génicos (aadA, aadB, aac (6)-Iq, orfD, dfrA17 y aadA5) (Tabla 2). El producto de $1000 \mathrm{pb}$ presente en las cepas 09, 11, 13 y 15 mostró $100 \%$ de similitud con el gen aadA1 (número de acceso DQ141317), el cual codifica la enzima aminoglicósido 2'-O-adeniltransferasa, que confiere resistencia a los aminoglucósidos estreptomicina y espectomicina, mientras que el producto de $750 \mathrm{pb}$ codifica para el gen $a a d B$ (número de acceso DQ141319) el cual confiere resistencia a gentamicina, tobramicina y kanamicina.

El producto amplificado de 1.200 pb presentó 
Caracterización de la región variable de integrones clase 1 presentes en Klebsiella pneumoniae - M. Guzmán et al

Tabla 2. Características de los casetes génicos encontrados en las cepas de Klebsiella pneumoniae y perfil de resistencia de las transconjugantes obtenidas

\begin{tabular}{|c|c|c|c|c|c|}
\hline Cepa & $\begin{array}{c}\text { Fenótipo de resistencia de las cepas } \\
\text { transconjugantes }\end{array}$ & $\begin{array}{l}\text { Tamaño } \\
\text { (pb) }\end{array}$ & $\begin{array}{l}\text { Número de } \\
\text { integrones }\end{array}$ & $\begin{array}{l}\text { Locali- } \\
\text { zación }\end{array}$ & Casete \\
\hline Kp09 & AMP AMK K TOB GEN Nt & 1000 & 1 & PNC & aadA1 \\
\hline Kp11 & AMP ATM CAZ CRO CTX AMK K TOB GEN Nt CHL & 1000 & 1 & PNC & aadA1 \\
\hline Kp13 & AMP ATM TZP CAZ CRO CTX AMK K TOB GEN Nt CHL FEP & 1000 & 1 & PC & aadA1 \\
\hline Kp14 & AMP ATM CAZ CRO CTX AMK K TOB GEN Nt CHL & $\begin{array}{l}1200 \\
2000\end{array}$ & 2 & PC & $\begin{array}{l}\text { aaC(6)-lq, } \\
\text { orfD; ND }\end{array}$ \\
\hline Kp15 & AMP ATM TZP CAZ CRO CTX AMK K TOB GEN Nt CHL FEP & 1000 & 1 & PC & aadA1 \\
\hline Kp25 & AMP ATM TZP CAZ CRO CTX AMK K TOB GEN Nt CHL & 1700 & 1 & PNC & $\begin{array}{l}\text { dfrA17, } \\
\operatorname{aadA5}\end{array}$ \\
\hline Kp26 & AMP ATM TZP CAZ CRO CTX AMK K TOB GEN Nt CHL & 1700 & 1 & PNC & $\begin{array}{l}\text { dfrA17, } \\
\operatorname{aad} A 5\end{array}$ \\
\hline Kp27 & AMP ATM TZP CAZ CRO CTX AMK K TOB GEN Nt CHL & 1700 & 1 & PNC & $\begin{array}{l}\text { dfrA17, } \\
\operatorname{aadA5}\end{array}$ \\
\hline Kp28 & AMP ATM TZP CAZ CRO CTX AMK K TOB GEN Nt & 750 & 1 & PC & aadB \\
\hline Kp29 & AMP ATM TZP CAZ CRO CTX AMK K TOB GEN Nt & 750 & 1 & PC & aadB \\
\hline
\end{tabular}

AMK: Amikacina, ATM: Aztreonam, CAZ: Ceftazidima, CHL: Cloramfenicol, CIP: Ciprofloxacina, CRO: Ceftriaxona, CTX: Cefotaxima, FEP: Cefepima, GEN: Gentamicina, K: Kanamicina, Nt: Netilmicina, OFX: Ofloxacina, TCY: Tetraciclina, TOB: Tobramicina, TZP: piperacilina-tazobactam, Kp: Klebsiella pneumoniae, Pb: pares de bases, PNC: Plásmido no conjugativo, PC: Plásmido conjugativo.

dos casetes génicos, aac(6)-Iq (número de acceso AF047556), el cual confiere resistencia a amikacina, tobramicina y gentamicina, y otro reportado como orfD en Klebsiella pneumoniae (número de acceso AM040449) que permanece como un marco abierto de lectura, de función desconocida.

La región de 1700 pb también presentó dos casetes génicos. Uno que corresponde al gen $d f r A 17$ (número de acceso AF220757) que codifica una dihidrofolato reductasa, que confiere resistencia a trimetoprim, y otro que tiene similitud con el gen aadA5 (número de acceso AF220757) que confiere resistencia a amikacina y a tobramicina. El producto de $2.000 \mathrm{pb}$ no pudo ser secuenciado.

\section{Discusión}

En los últimos años K. pneumoniae ha adquirido diversos mecanismos de resistencia a los antimicrobianos de uso frecuente en el tratamiento de las enfermedades infecciosas, lo que trae como consecuencia serias dificultades en el tratamiento de los pacientes ${ }^{11,12}$. En K. pneumoniae, la resistencia suele asociarse con mayor frecuencia a la expresión de genes presentes en plásmidos, transposones e integrones, los cuales son elementos claves en la transmisión horizontal de la información genética, debido a que son capaces de propagar la resistencia entre los miembros de una misma o diferentes especies ${ }^{22,23}$. En este estudio se encontró que todas las cepas presentaron elevados porcentajes de resistencia a los antimicrobianos de uso frecuente en el tratamiento de las infecciones causadas por enterobacterias, hecho que genera una disminución en las posibilidades terapéuticas, para tratar las infecciones ocasionadas por esta bacteria en el centro hospitalario.

El integrón clase 1 es el más estudiado en 
bacterias Gram negativas, y su presencia se ha reportado en la gran mayoría de las especies que conforman la familia Enterobacteriaceae, así como en otros microorganismos pertenecientes a otras familias ${ }^{24,25}$. En este trabajo, 34,48\% de las cepas presentaron integrones clase 1 . $\mathrm{Al}$ respecto, Reyes et $\mathrm{al}^{26}$, en Chile, demostraron la presencia de integrones clase 1 en cepas de $K$. pneumoniae y E. coli, mientras que a nivel nacional, Alonso et $\mathrm{al}^{27}$ reportaron la presencia de integrones clase 1 en diferentes especies de enterobacterias aisladas de diferentes ambientes en Venezuela.

Todos los integrones detectados en este trabajo estaban localizados en plásmidos, sólo el integrón de 1000 pb se encontró tanto en plásmidos conjugativos como no conjugativos, hecho que soporta la transferencia horizontal de genes en las cepas de K. pneumoniae estudiadas. Esta observación además permite inferir que los integrones pudieran estar asociados a secuencias de inserción o transposones, los cuales también garantizan su diseminación mediante transferencia horizontal. Zhang et $\mathrm{al}^{28}$ sugieren que la amplia distribución de los casetes génicos presentes en un integrón, ha sido generada por la transferencia de plásmidos de amplio rango del hospedero. Nuestros resultados concuerdan con los reportados por ÁlvarezFernández et $\mathrm{al}^{29}$, quienes encontraron integrones clase 1 en plásmidos conjugativos en cepas nosocomiales de enterobacterias y con los de Torres et $\mathrm{al}^{30}$, quienes reportaron integrones localizados en plásmidos conjugativos y no conjugativos en cepas nosocomiales de K. pneumoniae, E. coli y Proteus.

En la región variable de los integrones clase 1 se han reportado aproximadamente 100 casetes génicos que confieren resistencia a una amplia gama de compuestos antibacterianos, que incluyen antibióticos $\beta$-lactámicos, aminoglucósidos, trimetoprim, sulfonamidas, fenicoles, tetraciclinas, rifampicina, eritromicina y quinolonas, siendo los genes que confieren resistencia a aminoglucósidos los que con mayor frecuencia se han reportado ${ }^{31,32}$. Los estudios de secuenciación de la región variable de los integrones clase 1, revelaron que éstos codifican para dos clases de enzimas: enzimas modificantes de aminoglucósidos y dihidrofolato reductasa. De acuerdo con los genes detectados ( $\operatorname{ad} A 1, \operatorname{aadB}, \operatorname{acc}(6)-I q, \operatorname{aad} A 5 \mathrm{y} d f r A 17)$ se demuestra que todos los integrones codifican para enzimas modificadoras de aminoglucósidos. La presencia de estos genes coincide con el fenotipo de resistencia presentado por las cepas, sin embargo, al observar los distintos patrones de resistencia, se puede inferir la presencia de otros genes de resistencia a aminoglucósidos no detectados en estos elementos genéticos.

Los aminoglúcosidos son antimicrobianos ampliamente utilizados en el tratamiento de las infecciones nosocomiales. La presión selectiva generada por ellos en el centro hospitalario pudiera explicar la presencia y permanencia de los genes en las cepas de K. pneumoniae. El casete aadA1 fue el que se logró identificar con mayor frecuencia ( 5 cepas), seguido de aadA5-dfrA17 (tres cepas), $a a d B$ (dos cepas) y aac (6)-Iq (1 cepa).

El casete aadA codifica resistencia a espectomicina y estreptomicina; estos antimicrobianos actualmente son poco usados como opción terapéutica. Sin embargo, se ha demostrado que los casetes génicos aadA pueden permanecer en un integrón aun cuando no exista presión selectiva o cese el uso de estos antimicrobianos ${ }^{33,34}$.

El gen $d f r A 17$ confiere resistencia a trimetoprim, mientras que el gen aadA5 codifica una 3Q-adeniltransferasa que confiere resistencia a espectomicina y estreptomicina. La presencia de estos genes ha sido detectada en otros miembros de la familia Enterobacteriaceae y Pseudomonadaceae a nivel mundial ${ }^{35}$. Se ha reportado que la selección del casete $d f r A 17$ encontrado en cepas de Klebsiella pneumoniae y E. coli, se debe al uso de trimetoprim como opción terapéutica en el tratamiento de infecciones urinarias ${ }^{33,37}$.

El casete génico $a a d B$ confiere resistencia a gentamicina, tobramicina y kanamicina. Este casete ha sido reportado en plásmidos transferibles presentes en cepas de Klebsiella spp resistentes a gentamicina y asociados a la presencia del gen $b l a_{\mathrm{SHV}}$ en cepas productoras de $\beta$-lactamasas de espectro extendido ${ }^{38}$.

El casete $a a c(6)-I q$ codifica para una acetiltransferasa que confiere resistencia a amikacina. Este casete ha sido reportado en cepas de Klebsiella pneumoniae y Salmonella. La secuencia de este casete tiene similitud con otros genes como $a a C(6)$ Ia, $a a C(6)-I p$ y $a a C(6)-I t$. En $a a c(6)-I q$ la presencia del codón de inicio TTG en lugar de ATG, genera un bajo nivel de expresión a la amikacina ${ }^{39,40}$.

Los integrones clase 1 se han reconocido como elementos genéticos importantes en la evolución del genoma bacteriano, razón por la cual juegan un papel importante en la captación y diseminación 
de genes de resistencia entre cepas de diferentes ambientes. En este trabajo se pudo determinar la presencia de integrones en plásmidos y los distintos casetes génicos localizados en la región variable, responsable de la resistencia principalmente a aminoglucósidos en las cepas.

\section{Referencias}

1. Gupta A, Ampolo K, Rubenstein D, Saiman L. Extended spectrum b-lactamase-producing Klebsiella pneumoniae infections: a review of the literature. J Perinatol 2003; 23: 439-43.

2. Carattoli A. Plasmid-mediated antimicrobial resistance in Salmonella enterica. Curr Issues Mol Biol 2003; 5: 113-22.

3. Rowe-Magnus DA, Davies J, Mazel D. Impact of integrons and transposons on the evolution of resistance and virulence. Curr Top Microbiol Immunol 2002; 264: 167-88.

4. Partridge SR, Brown H, Stokes W, Hall RM. Transposons Tn1696 and Tn21 and their integrons In 4 and In 2 have independent origins. Antimicrob Agents Chemother 2001; 45: 1263-70.

5. Collis C, Hall R. Expression of antibiotic resistence genes in the integrated cassettes of integrons. Antimicrob Agents Chemother 1995; 39: 155-62.

6. Hall R, Stokes H. Integrons. Novel DNA elements which capture genes by site-specific recombinations. Genetics 1993; 90: 115-32.

7. González G, Mella S, Zemelman R, Bello H, Domínguez Y. Integrones y cassettes genéticos de resistencia: estructura y rol frente a los antibacterianos. Rev Med Chile 2004; 132: 619-26.

8. Stokes H, Hall R. A novel family of potentially mobile DNA elements encoding site specific gene integration functions: integrons. Mol Microbiol 1989; 3: 1669-83.

9. Collis C, Hall R. Site-specific deletion and rearrangement of insert genes catalyzed by the DNA integrase. J Bacteriol 1992; 174: 1574-85.

10. Fluit A, Schmitz FJ. Resistance integrons and superintegrons. Clin Microbiol Infec 2004; 10: 272-88.

11. Podschum R, Ullmann U. Klebsiella spp. as nosocomial pathogens: Epidemiology, taxonomy, typing methods, and pathogenicity factors. Clin Microbiol Rev 1998; 11: 589-603.

12. Gales C, Jones R, Gordon K, Sader H, Wilke W, Beach M. Activity and spectrum of antimicrobial agents tested again urinary tract infection pathogens in hospitalized patients in Latin América: report from the second year of the SENTRY antimicrobial surveillance program. J
Antimicrob Chemother 1998; 45: 295-303.

13. Byarugaba D. View on antimicrobial resistance in developing countries and responsable risk factors. Int J Antimicrob Agents 2004; 24: 105-10.

14. Yang $\mathrm{H}$, Chen $\mathrm{H}$, Yang Q, Chen $\mathrm{M}$, Wang H. High Prevalence of Plasmid-Mediated Quinolone Resistance Genes $q n r$ and $a a c(6)-I b-c r$ in Clinical Isolates of Enterobacteriaceae from Nine Teaching Hospitals in China. Antimicrob Agents chemother 2008; 52: 4268-73.

15. Yao F, Quian Y, Chen S, Wang P, Huang Y. Incidence of Extended-spectrum b-lactamases and characterization of integrones in extended-spectrum $\beta$-Lactamaseproducing Klebsiella pneumoniae Isolated in Shantou, China. Acta Bioch Bioph Sin 2007; 39: 527-32.

16. Shi W, Zhou J, Quin J. Transconjugation and genotyping of the plasmid-mediated AmpC b-lactamase and extended-spectrum b-lactamase genes in Klebsiella pneumoniae. Chi Med J 2009; 12: 1090-6.

17. Clinical and Laboratory Standards Institute (CLSI). Performance standards for antimicrobial susceptibility testing; eigthteenth informational supplement, M100S18. CLSI 2008. Wayne, PA.

18. Levesqué C, Pichel L, Larose C, Roy P. PCR mapping of integron reveals several novel combinations of resistance genes. Antimicrob Agents Chemother 1995; 39: 185-91.

19. Narváez P, Pedroza R, Alonso G, Rodríguez-Lemoine V. Caracterización de plásmidos de resistencia a antibióticos en aislados nosocomiales del Hospital Universitario de Caracas. Rev Soc Ven Microbiol 2005; 25: 29-34.

20. Sambrook I, Russell D. Molecular cloning a laboratory manual. $3^{a}$ Edition. Cold Spring Harbor: New York: 2001.

21. Altschul SF, Madden TL, Schaffer AA, et al. Gapped BLAST and PSI-BLAST: a new generation of protein database search programs. Nucleic Acids Res 1997; 25: 3389-402.

22. Essack S, Hall L, Livermore D. Klebsiella pneumoniae isolate from South Africa with multiple TEM, SHV and AmpC $\beta$-lactamases. Int J Antimicrob Agents 2004; 23: 398-400.

23. Schjorring S, Struve C, Krogfelt KA. Transfer of antimicrobial resistance plasmids from Klebsiella pneumoniae to Escherichia coli in the mouse intestine. J Antimicrob Chemother 2008; 62: 1086-93.

24. Labuschange C, Weldhagen GF, Ehlers MM, Dove MG. Emergence of class 1 integron-associated GES-5 and GES-5-like extended-spectrum beta-lactamases in clinical isolates of Pseudomonas aeruginosa in South Africa. Int J antimicrob Agents 2008; 31: 527-30.

25. Boucher Y, Labbate M, Koenig JE, Stokes HW. Integrons: mobilizable platforms that promote genetic diversity in 
bacteria. Trends Microbiol 2007; 15: 301-309.

26. Reyes A, Bello H, Domínguez M, Mella S, Zemelman R, Gonzáles G. Prevalence and types of class 1 integrons in aminoglycoside-resistant Enterobacteriaceae from several Chilean hospitals. J Antimicrob Chemother 2003; 51: 317-21.

27. Alonso G, Malaver E, Guzmán M, Rodríguez V. Caracterización de plásmidos e integrones presentes en bacterias multirresistentes aisladas en diferentes ambientes de Venezuela. MIBE 2005; 4: 81-84.

28. Zhang H, Shi L, Li L, Guo S, Zhang X, Yamasaki S, et al. Identification and Characterization of Class 1 Integron Resistance Gene Cassettes among Salmonella Strains Isolated from Healthy Humans in China. Microbiol Immunol 2004; 48: 639-45.

29. Álvarez-Fernández M, Rodríguez-Sousa T, Brey-Fernández E, López-Meléndez C, Piñeiro L. Asociación entre integrones de clase 1 con resistencia a múltiples antimicrobianos y plásmidos conjugativos en Enterobacteriacea. Rev Esp Quimioterap 2003; 16: 394-7.

30. Torres L, Benítez M, Domínguez M, Torres O, Gagliotta V, Calvo A, et al. Detección de integrones clase 1 en cepas de enterobacterias productoras de -lactamasas de espectro expandido tipo SHV y CTX-M grupo 2. VITAE Academia Biomédica digital. 2005; 25: Disponible en http;/caibco.ucv.ve. [Acceso 2 de julio de 2008].

31. Fluit Ac, Schmitz J. Class 1 integrons, gene cassettes mobility, and epidemiology. Eur J Clin Microbiol Infect Dis 1999; 18: 761-70.

32. Wu JJ, Ko WC, Tsai SH, Yan JJ. Prevalence of plasmidmediated quinolone resistance determinants QnrA, QnrB, and QnrS among clinical isolates of Enterobacter cloacae in a Taiwanese hospital. Antimicrob Agents Chemother 2007; 51: 1223-7.

33. White P, Melver C, Rawlinson W. Integrons and gene cassette in Enterobacteriaceae. Antimicrob Agents Che- mother 2001; 45: 2658-61.

34. Pallecchi L, Lucchetti C, Bartoloni A, Bartalesi F, Mantella A, Gamboa H, et al. Population Structure and Resistance Genes in Antibiotic-Resistant Bacteria from a Remote Community with Minimal Antibiotic Exposure. Antimicrob Agents Chemother 2007; 51: 1179-84.

35. Lee JC, Oh JY, Cho JW, Park JC, Kim JM, Seol SY, et al. The prevalence of trimethoprim-resistance-conferring dihydrofolate reductase genes in urinary isolates of $E s$ cherichia coli in Korea. J Antimicrob Chemother 2001; 47: 599-604.

36. France A, Kugeler KM, Freeman A, Zalewski CA, Blahna M, Lixin Z, et al. Clonal Groups and the Spread of Resistance to Trimethoprim-Sulfamethoxazole in Uropathogenic Escherichia coli. Clin Infect Dis 2005; 40: 1101-7.

37. Yu HS, Lee JC, Kang HY, Jeong YS, Lee EY, Choi CH, et al. Prevalence of $d f r$ genes associated with integrons and dissemination of $d f r A 17$ among urinary isolates of Escherichia coli in Korea. J Antimicrob chemother 2004; 53: 445-50.

38. Jones L, Mclver C, Kim M, Rawlinson W, White P. The $a a d B$ gene cassette is associated whith $b l a_{\mathrm{SHV}}$ genes in Klebsiella species producing extended-spectrum -lactamases. Antimicrob Agents Chemother 2005; 49: 794-7.

39. Centron D, Roy PH. Characterization of the 6'-Naminoglycoside acetyltransferase gene $a a c\left(6^{\prime}\right)-I q$ from the integron of a natural multiresistance plasmid. Antimicrob agents Chemother 1998; 42: 1506-8.

40. Fonseca EL, Mykytczuk OL, Asensi MD, Reis EM, Ferraz LR, Paula FL, et al. Clonality and Antimicrobial Resistance Gene Profiles of Multidrug-Resistant Salmonella enterica Serovar Infantis Isolates from Four Public Hospitals in Rio de Janeiro, Brazil. J Clin Microbiol 2006; 4: 2767-72. 